\title{
Weaving an interpretivist stance throughout mixed methods research
}

\author{
Katrina McChesney and Jill M. Aldridge
}

\section{This is the authors' accepted manuscript.}

The Version of Record of this manuscript was published on 27 March 2019 and is available in the International Journal of Research and Method in Education, 42(3), 225-238

https://www.tandfonline.com/doi/full/10.1080/1743727X.2019.1590811

\begin{abstract}
A recurring debate in mixed methods research involves the relationship between research methods and research paradigms. Whereas some scholars appear to assume that qualitative and quantitative research methods each necessarily belong with particular research paradigms, others have called for greater flexibility and have taken a variety of stances toward the integration of paradigms and methods in mixed-method studies. In this article, we review these arguments and stances, positioning ourselves in favour of flexible (but intentional) integration of any research method with any research paradigm. We then draw on a recent study of teachers' experiences of professional development to provide an illustration of how a single paradigm can be used to inform the entirety of a mixed methods study, including study design, data collection, analysis and reporting. This illustration is particularly noteworthy since past mixed-method studies that have been grounded in a single paradigm have typically used the post-positivist paradigm, whereas our study involved an interpretive stance and a social constructivist epistemology. This article may, therefore, provide a useful resource for those considering the design of mixed methods studies as well as a practical demonstration to support theoretical claims in support of moving away from binary methods-paradigm associations and assumptions.
\end{abstract}

\section{Keywords:}

Mixed methods research; interpretivist paradigm; cross-cultural research; social constructivist research; paradigm; teacher voice; professional development 


\section{Disclosure statement:}

No potential conflict of interest was reported by the authors.

\section{Funding:}

The research reported in this article was supported by an Australian Government Research Training Programme Scholarship and a Curtin University PhD Completion Scholarship.

\section{ORCID:}

Katrina McChesney http://orcid.org/0000-0002-3991-6265

Jill Aldridge http://orcid.org/0000-0003-0742-0473

\section{Corresponding author:}

Katrina McChesney

Te Kura Toi Tangata School of Education

University of Waikato - Tauranga

New Zealand

k.mcchesney@waikato.ac.nz 


\section{Weaving an interpretivist stance throughout mixed methods research Katrina McChesney and Jill M. Aldridge}

\section{Introduction}

Over the past three decades, the field of mixed methods research has grown and developed in many ways (Tashakkori and Creswell 2007, Creswell 2010). Extensive debate, analysis and experimentation have unfolded as researchers have explored ways to combine quantitative and qualitative data within research studies as well as ways to understand and describe how we do so. Practical considerations around 'mixing' or integrating qualitative and quantitative elements have naturally been a major focus of this development (Teddlie and Tashakkori 2003, Yin 2006, Bazeley 2009, Creswell and Plano Clark 2011, Creamer 2018), as have considerations around what really 'counts' as mixed methods research (Tashakkori and Creswell 2007, Fetters and Molina-Azorin 2017, Creamer 2018). However, another recurring — and, as yet, unresolved — topic of discussion has concerned the relationship between methods and paradigms in mixed methods research (see, for example, Greene and Caracelli 1997, Johnson and Onwuegbuzie 2004, Morgan 2007, Bazeley 2009, Bergman 2010, Creswell and Plano Clark 2011, Mertens 2012, Shannon-Baker 2016, Fetters and Molina-Azorin 2017, Hathcoat and Meixner 2017). Arguably, the lack of clarity around appropriate paradigmatic foundations for mixed methods research may have contributed to the concerns of 'many theorists, methodologists, and empirical researchers [who] remain apprehensive, considering [mixed methods research] insufficiently rigorous' (Bergman 2010, 271). Some progress in the reputation of mixed methods research has been made since Bergman's characterisation (Fetters and Molina-Azorin 2017); however, confusion and conflicts around method-paradigm associations remain, and it is into this space that we hope to contribute through the current article. 
This article is in three major parts. After clarifying our conceptual framework, we begin by exploring the relationship between methods and paradigms in mixed methods research and the different stances taken by researchers in addressing this relationship. Our major conclusion from this review is that research paradigms do not each come with associated categories of 'acceptable methods' but, rather, that researchers have both the freedom and the responsibility to select methods that suit their research aims and to enact these methods in ways that are consistent with their paradigmatic choices. Given this conclusion, the second part of the article provides a precis of a recent mixed-methods study that was underpinned by the interpretivist paradigm. This is arguably an unusual paradigmmethods combination and so the study we summarise here serves to illustrate the intentionality needed when combining methods and paradigms in mixed methods research. The final part of this article suggests possible ways forward for mixed methods researchers seeking to combine research methods within a single paradigm with integrity.

This article contributes to a wider discussion about the relationship between methods and paradigms in mixed methods research. It offers an exemplar of a study that was not only rich in the interweaving of its qualitative and quantitative elements but that was also coherently underpinned by an interpretivist paradigm; this exemplar may be of use to those considering the design of other mixed methods studies. We do not wish to imply that the use of a single overarching paradigm is the only way to conduct a mixed methods study, but we do hope to demonstrate that this is a viable option and, in particular, that the interpretivist paradigm can be used in this way.

\section{Conceptual framework}

\section{Mixed methods research}

Mixed methods research has been defined as the use of two or more research methods 
(generally including both qualitative and quantitative methods) in a single research project (Johnson, Onwuegbuzie et al. 2007, Tashakkori and Creswell 2007, Greene 2008, Teddlie and Tashakkori 2009, Creswell and Plano Clark 2011). It has been argued that using a mixed method design can be superior to using a single-method design as it can: provide a better understanding of the phenomenon under investigation; overcome weaknesses inherent in either qualitative or quantitative approaches alone; allow triangulation of information; provide information that cannot be answered using one method alone; address different aspects of a research topic (for example, both confirmatory and exploratory questions) simultaneously; and allow stronger inferences to be drawn (Teddlie and Tashakkori 2003, Greene 2005, Teddlie and Tashakkori 2009, Creamer 2018). Moreover, mixed methods research has particular relevance for educational research because this approach 'not only provides but actually creates spaces for a full engagement with the challenges of understanding teaching and learning as complex processes' (Greene 2005, 211; see also Alise and Teddlie 2010).

Research involving mixed methods should, by definition, involve the blending or mixing of methods at some or all stages of the study (Yin 2006, Tashakkori and Creswell 2007); this blending can occur sequentially or concurrently (Creswell and Plano Clark 2011). In much mixed-method research, however, although both qualitative and quantitative data may be collected, the actual mixing of qualitative and quantitative methods is often limited (Yin 2006, Bryman 2007, Alise and Teddlie 2010). Many such studies involve sets of research questions and inferences that are each either solely qualitative or solely quantitative in nature, with a mix of both types (qualitative and quantitative) being provided across the study as a whole (Teddlie and Tashakkori 2003, Yin 2006, Bryman 2007, Tashakkori and Creswell 2007). 
Although we acknowledge (and support) the calls for mixed-methods studies to demonstrate genuine integration of their qualitative and quantitative components so that 'the end product is more than the sum of the individual quantitative and qualitative parts' (Bryman 2007, 8), we recognise that that vision has not yet been fully realised in the field (Alise and Teddlie 2010). In this article, therefore, we use a broad definition of mixed methods research as being research that involves both qualitative and quantitative methods.

It should be noted that in this article we focus on the idea of 'methods' rather than 'methodologies'. Following the advice of Guba and Lincoln $(1989,158)$, we understand methods to be the 'tools and techniques' with which data are collected and analysed, whereas methodologies are 'overall guiding strategies' encompassing both methods and paradigmatic or philosophical positionings (see also Mackenzie and Knipe 2006, Creswell 2010). Our interest, for this article, is in the relationship between the methods and paradigm(s) that comprise the overarching methodology for a research study.

\section{Research paradigms and the interpretivist paradigm}

The term 'paradigm' in terms of research originated with Kuhn (1970), who described a paradigm as an epistemological stance that determines the types of questions that are asked and then understood. Subsequently, however, paradigms have been conceptualised in various ways, including as worldviews, epistemological stances, shared beliefs held by a community of researchers, and exemplars of research (Mackenzie and Knipe 2006, Bryman 2007, Morgan 2007, Bergman 2010). Even mixed methods research itself has been described as 'the third research paradigm' (Johnson and Onwuegbuzie 2004, 14), further stretching the possible meanings of the word 'paradigm'. Most commonly, however, the term has been used to describe 'a worldview, together with the various philosophical assumptions associated with that point of view' (Teddlie and Tashakkori 2009, 84; see also Greene 2008, Creswell and Plano Clark 2011); we use the term in such a way in this article. Researchers' worldviews or 
paradigms, in this interpretation, 'determine the kind of questions researchers ask, how these questions are to be understood, what data to collect, and how to interpret research results to derive answers to these questions' (Bergman 2010, 172).

Although a range of paradigms have been identified (Lincoln and Guba 2003), paradigms that are widely recognised within social research include the post-positivist, constructivist/interpretivist, critical/transformative and pragmatist paradigms (Mackenzie and Knipe 2006, Shannon-Baker 2016). The interpretivist paradigm was used in the research reported later in this article and so is introduced briefly here. In an interpretivist worldview, although an external reality is believed to exist, it is not expected that this reality can be objectively captured by scientific research (Willis 2007). Instead, the goal of interpretivist research is to 'understan[d] the complex world of lived experience from the point of view of those who live it' (Schwandt 1998, 221). Interpretivist research is, thus, 'a socially constructed activity, and the "reality" it tells us about therefore is also socially constructed" (Willis, 2007, 96). The knowledge arising from interpretivist research is integrally linked to the participants and the context of the research, meaning that the products of interpretivist research are not universally applicable theories or laws but, rather, rich and contextually situated understandings. We return to the interpretivist paradigm later in providing a summary of our recent research study; now, however, we consider past discussions around the paradigmatic foundations for mixed methods research.

\section{The relationship between paradigms and methods in mixed methods research}

Paradigms have an important role in mixed methods research, as with other types of research. However, justifying the alignment between paradigm(s) and research methods in a mixed-methods study can be confounding (Johnson and Onwuegbuzie 2004, Hall 2013). Perhaps for this reason, many accounts of mixed-methods studies do not explicitly identify their paradigmatic foundations or how these were linked with research methods (Alise and 
Teddlie 2010), giving such studies the appearance of lacking a robust philosophical foundation (Hall 2013). This section outlines the different ways scholars have attempted to resolve the relationship between paradigms and methods in mixed methods research. It should be noted that in summarising these various approaches, we are not necessarily endorsing them; our own stance is identified at the end of this section.

Some scholars have taken what we term a binary stance toward the relationship between research methods and paradigms. Citing the philosophical differences between quantitative and qualitative research, these scholars have suggested that quantitative and qualitative methods are each situated within particular paradigms - the former 'belonging' with objectivist, positivist, or post-positivist paradigms and the latter 'belonging' with subjectivist, constructivist, critical, postmodern, feminist, interpretivist, and other associated paradigms (Greene and Caracelli 1997, Johnson and Onwuegbuzie 2004, Mackenzie and Knipe 2006, Onwuegbuzie, Johnson et al. 2009, Creswell and Plano Clark 2011). Some scholars have taken strict, 'purist' stances on this topic (Onwuegbuzie and Leech 2005) whereas others have taken softer stances, saying (for example) that qualitative or qualitative studies 'tend to or typically use' particular paradigms (Creswell 2014, 18). In either case, however, the message is that particular methods effectively belong with particular paradigms.

Although such binary categorisations may 'work' for (at least much) single-method research, they are problematic for mixed methods research because of claims that the various paradigms are incommensurable or incompatible (Kuhn 1970, Lincoln 1990). If qualitative and quantitative approaches align with different paradigms, but these paradigms are incommensurable, then how can it ever be meaningful to combine qualitative and quantitative approaches in a 'mixed methods' study? With this question unresolved, the echoes of binary method-paradigm associations have arguably contributed to the proliferation of so-called 
mixed methods studies that in fact involve little genuine integration of their qualitative and quantitative elements (Yin 2006, Tashakkori and Creswell 2007).

It has been argued, however, that 'although many research procedures or methods typically have been linked to certain paradigms, this linkage between research paradigms and research methods is neither sacrosanct nor necessary' (Johnson and Onwuegbuzie 2004, 14; see also Guba and Lincoln 1994, Crotty 1998, Bergman 2010, Biesta 2010, Gray 2013, Hathcoat and Meixner 2017). As such, to overcome the problems that have been associated with the use of paradigms in mixed methods research, researchers have taken a number of different stances, including a-paradigmatic, dual-paradigm (or dialectical), pragmatist, and single-paradigm approaches (Mertens 2012, Hall 2013). Below, we review these alternative stances.

\section{The a-paradigmatic stance}

The first stance taken by some mixed methods researchers is an a-paradigmatic approach. A-paradigmatic researchers argue that 'paradigms could be important for methodology but should not be used to inform the inquiry process' (Shannon-Baker 2016, 320). This approach effectively side-steps or ignores paradigm-related questions in the service of 'what works' (or, at times, what gets funded; Bryman 2007, Hall 2013), threatening the credibility, coherence and validity of the resulting research.

\section{The dual-paradigm or dialectical stance}

The second stance involves a dual or dialectical perspective that 'welcomes more than one paradigmatic tradition and mental model, along with more than one methodology and type of method, into the same inquiry space and engages them in respectful dialogue one with the other throughout the inquiry' (Greene and Hall 2010). Many mixed methods researchers argue that it is possible to combine two (or even more) worldviews or paradigms within a 
single research project and that doing so may generate 'more comprehensive, insightful, and logical results than either paradigm could obtain alone' (Greene and Caracelli 1997, 10). Studies using such a dialectical stance might include some research questions situated in each paradigm (for example, post-positivist and constructivist), thus reflecting the two different worldviews (Teddlie and Tashakkori 2009). Johnson $(2017,159)$ has taken a further step, proposing that 'dialectical pluralism' may, in fact, constitute a metaparadigm that 'recommends that one concurrently and equally value multiple perspectives and paradigms.'

Despite these arguments in favour of dialectical approaches, there is nonetheless considerable debate around whether mixed methods research involving more than one paradigm is, indeed, possible, considering the purported incompatibility or incommensurability of distinct paradigms (see, for example, Kuhn 1970, Lincoln 1990, Guba and Lincoln 1994). Given this complexity, mixed methods researchers wishing to use a dualparadigm approach need to carefully consider how the different philosophical approaches (that is, the two paradigms) they intend to use can be interrelated and how the research methods will preserve genuine multiplicity. The reduction of one paradigmatic approach in favour of the other must be avoided if a truly dual/dialectical stance is sought. At the same time, care must be taken to avoid the issue that characterises many supposedly mixedmethods studies: the separation of components of the study along methodological or paradigmatic grounds to the point where the result is really two parallel but distinct studies on the same research topic (Yin 2006, Alise and Teddlie 2010).

\section{The pragmatist stance}

Within the dual/dialectical stance, the incommensurability argument has given rise to the pragmatic paradigm (Onwuegbuzie and Leech 2005, Biesta 2010, Hathcoat and Meixner 2017). Advocates of the pragmatic approach maintain that although there are differences between paradigms, the various paradigms are 'logically independent and therefore can be 
mixed and matched, in conjunction with choices about methods, to achieve the combination most appropriate for a given inquiry' (Greene and Caracelli 1997, 8). This paradigm, therefore, offers researchers an epistemological justification for mixing approaches and methods (Onwuegbuzie and Leech 2005, Biesta 2010) and argues that the primary driver of research methods should not be the research paradigm(s) but rather the research question(s) (Biesta 2010, Shannon-Baker 2016).

Although this pragmatist approach may seem very similar to the dialectical approach described above (in terms of the acceptability of combining different research paradigms), pragmatist and dialectical approaches fundamentally differ in their levels of concern for philosophical matters. Critics have characterised pragmatism as 'the pacifier in the paradigm war' (Bergman 2010, 271), allowing researchers to effectively sideline paradigmatic concerns in an 'anything goes' manner (Greene 2007, Hall 2013) that may be logically inconsistent (Bazeley 2009, Hathcoat and Meixner 2017) or effectively equate to the a-paradigmatic stance described above. According to Denzin $(2012,83)$,

\footnotetext{
It is one thing to endorse pluralism [or dialecticalism] ... but it is quite another to build a social science on a what-works pragmatism. It is a mistake to forget about paradigm, epistemological, and methodological differences between and within QUAN/QUAL frameworks. These are differences that matter.
}

\section{The holistic or single-paradigm stance}

A final stance claims that both qualitative and quantitative methods can be accommodated within a mixed methods study using a single overarching paradigm. A number of scholars have argued that 'if it suits their purposes, any of the theoretical perspectives could make use of any of the methodologies' (Crotty 1998, 12; see also Guba and Lincoln 1994, Johnson and Onwuegbuzie 2004, Mackenzie and Knipe 2006, Gray 2013). On this basis, it seems reasonable to conduct the whole of a mixed methods study-including both qualitative and quantitative components - in accordance with a single research 
paradigm. This stance offers space for more varied and purposeful selection and integration of paradigms and methods in order to suit the aims of particular studies. For mixed methods researchers, this stance would appear to be, if not the only way of thoughtfully resolving methodological-paradigmatic alignment issues, certainly one productive way of doing so.

The idea of using a single, holistic paradigm for a mixed methods study is not new. In educational as well as other social research fields, many mixed methods studies have been conducted with such a stance (either implicitly or explicitly). However, perhaps influenced by the methodological conservativism of government and institutional funding policies, a large proportion of mixed methods research to date has been conducted with an overarching positivist or post-positivist stance (Giddings 2006, Alise and Teddlie 2010, Hesse-Biber 2010, Denzin 2012, Torrance 2012).

Constructivist or interpretivist paradigms have less frequently been used to frame entire mixed methods studies, however, and so having reviewed the arguments related to the relationship between research methods and research paradigms, we now provide an overview of a study of this nature. Our aim in doing so is to illustrate how an interpretivist stance and a social constructivist epistemology (both of which are traditionally associated with qualitative research, or the qualitative components of mixed methods research) were able to inform all aspects of a mixed methods study. By demonstrating how this approach can work in practice, we provide support for the claims that methods and paradigms can be used flexibly and in accordance with the aims of a particular research study (in contrast to the more binding assumptions that particular methods 'belong' with particular paradigms). We also provide a practical illustration of the use of an interpretivist paradigm as a holistic theoretical foundation for an entire mixed method study. This model may be of use for future researchers, given the relative lack of existing mixed methods studies that have been conducted from a solely interpretivist perspective. 


\section{An interpretivist mixed methods investigation of teachers' experiences of professional development}

In this section, we provide an overview of our recent study, highlighting how the interpretivist stance was reflected across the focus and aims, data sources, sampling techniques, data analysis and interpretation approaches, reporting and quality considerations of the study. It should be noted that, for reasons of space, what follows is not a full account of the study; our focus is on highlighting the decisions and considerations made in order for the various aspects of the study to coherently reflect our interpretivist stance. Thus, we do not detail all of the findings, nor do we provide full details of the methods used, the demographic breakdown of the sample or the ethical procedures followed. These and other details are available in the full account of the study (McChesney 2017).

\section{Focus and aims of the study}

The study we report here (McChesney 2017) involved an interpretivist mixed methods investigation of public school teachers' experiences of professional development ${ }^{1}$ within a major education reform in Abu Dhabi, United Arab Emirates. Teachers' lived experiences in relation to their involvement in professional development were the primary phenomenon of interest. The overarching intention of the research was not to provide an objective record or assessment of professional development activities (as may have been the focus of a postpositivist or pragmatist study) but, rather, to explore how teachers experienced, perceived and responded to the professional development that they had received in Abu Dhabi public schools. This focus reflected the interpretivist principle that understanding (rather than

\footnotetext{
${ }^{1}$ For the purposes of both the original study and the present article, the term professional development refers to 'any activities that caused, or were intended to cause, teacher learning. These activities may have been planned, spontaneous, formal, or informal' (McChesney, 2017, 32).
} 
explaining, generalising or critiquing) is the fundamental aim of research (Willis 2007).

Our study was also intended to provide 'understanding of the topic of study in context' (Willis 2007, 105; emphasis added). We did not seek to identify universally applicable factors that affected the impact of professional development for all teachers in all contexts. Rather, we wanted to understand what was going on for the teachers in Abu Dhabi public schools - what aspects of their contexts, what personal characteristics, and what features of the professional development affected the outcomes that arose following professional development. This focus was consistent with the interpretivist stance, which emphasises 'the situatedness' of knowledge (Willis 2007, 99) rather than a search for generalisations or universal laws.

Within these broad intentions, the specific research objectives for the study were:

(1) To examine teachers' perceptions of the design and impact of professional development in Abu Dhabi public schools;

(2) To investigate relationships between the design and impact of professional development;

(3) To investigate non-design-related factors that affected teachers' perceptions of the impact of professional development; and

(4) To compare Arab and Western teachers' perceptions of professional development (McChesney 2017) $)^{2}$

\footnotetext{
${ }^{2}$ A further objective related to the development and validation of the questionnaire used in the main survey. As this was a methodological objective that served as a 'stepping stone' (by providing a survey tool suitable for use to conduct the intended research), it is not discussed further in this article; we refer interested readers to McChesney (2017) and McChesney and Aldridge (2018).
} 
These research objectives were intended to acknowledge that teachers were likely to have different experiences and perceptions of professional development — that is, that different teachers would make different meaning of the professional development offered to them. As such, the objectives were consistent with the constructivist ontology and epistemology associated with interpretivist research (Willis 2007).

The verbs chosen for the research objectives - to investigate, to examine and to compare - all offered space for both quantitative and qualitative data and the exploration of teachers' experiences and perceptions (Tashakkori and Creswell 2007). Verbs such as to measure and to evaluate were deliberately avoided, given that these verbs may be interpreted as having more post-positivist and deterministic connotations. The use of the noun impact was considered carefully, noting that this word may imply (post)positivistic measurement of outcomes. Ultimately, this word was retained given its prominence in the associated literature in the field of professional development; however, care was taken to conceptualise 'impact' broadly as encompassing a range of possible outcomes that may arise from professional development activities (including affective reactions, choices and responses), as well as to emphasise that we did not seek to objectively measure 'impact' but rather to explore teachers' perceptions of the impacts of professional development.

Although three of the above research objectives were defined at the outset of the study, one (investigating the non-design-related factors that affected the impact of professional development) was added after data collection and analysis had begun. Past literature had indicated the importance of various design features for promoting the impacts of professional development (Garet et al. 2001; Desimone, 2009), but the teachers in our study also highlighted the importance of other, non-design-related factors in affecting the impacts of professional development. Adding a new research objective to explore these additional factors reflected our interpretivist focus on understanding teachers' lived 
experiences along with the acceptability, to interpretivist researchers, of 'approaches that leave open the opportunity to discover things as the research progresses' (Willis 2007, 131).

\section{Data sources}

Given that teachers' experiences and perceptions formed the focus of the study, all data were collected from teachers. Whereas a more objectivist study of professional development may have involved school leaders, professional development providers, policymakers and/or students as additional participants (for example, to allow verification or critique of teachers' accounts), our study privileged teacher voice and accepted teachers' accounts as reflecting their constructions of reality.

The research involved both qualitative and quantitative data. Willis (2007, 109-110) tells us that interpretivist researchers:

don't always abandon standards such as the rules of the scientific method; they simply accept that whatever standards are used are subjective, and therefore potentially fallible, rather than objective and universal. Interpretivists accept almost all of the types of quantitative methods that positivists use, but they differ in how they interpret the results of quantitative research.

First, a questionnaire was developed to capture teachers' perceptions of the impact of professional development activities. This questionnaire was primarily quantitative, involving Likert-style items exploring teachers' perceptions of the extent to which various types of impact had arisen from professional development. At the end of the questionnaire, teachers were invited to add qualitative comments. This questionnaire is subsequently referred to as the 'main survey' data.

Second, 35 teachers participated in semi-structured interviews lasting approximately 90 minutes. During these interviews, teachers discussed their experiences of professional development and completed a second survey, referred to as the 'interviewee survey'. This 
survey contained the quantitative items from the main survey as well as additional items related to the design of professional development. Although the interviewee survey was solely quantitative, by including it as part of the interviews teachers were able to comment or ask questions as they wished, and subsequent interview questions drew on the teachers' survey responses. This approach allowed a rich interweaving of closely linked quantitative and qualitative data to be obtained.

\section{Sampling}

In designing the study samples, the primary consideration was to capture the diverse range of experiences held by members of the target population ${ }^{3}$. This focus reflected the interpretivist quest to understand participants' experiences and perspectives (Willis 2007). The first stage of sampling, therefore, involved inviting all teachers in the target population to respond to the main survey. This step was not expected to generate a comprehensive or representative sample across the target population but, rather, to offer any teacher who wished to express their views an opportunity to do so. The distribution of the resulting responses was reviewed and further data were collected through targeted visits to particular groups of teachers in order to assemble a sample that was approximately representative of the target population in terms of a number of demographic variables. After removing incomplete responses and responses from teachers outside the target population, the final main survey sample comprised 393 teachers.

\footnotetext{
${ }^{3}$ Based on the similarities and differences in the professional development provision for different groups of teachers in the research context, the target population was defined as teachers of English, mathematics or science subjects (including middle school science and high school biology, chemistry, geology, physics) at Grades 6-12 in public schools in the Emirate of Abu Dhabi.
} 
Purposive and snowball sampling (Cohen, Manion et al. 2007) were used to construct the sample for the interviews and interviewee survey. Purposive sampling was used to select a sample that reflected the experiences of a range of teachers, including according to the teachers' gender, teaching subjects, and ethnicity as well as their schools' locations and types. Snowball sampling, on the other hand, was used to ensure that the sample captured a wide range of different perspectives through asking interviewees to help identify other teachers who might bring alternative views. These sampling techniques again aligned with the interpretivist stance of the study, since interpretivists seek to capture 'the multiple perspectives that are inherent in most human endeavors' (Willis 2007, 161). Interviewing continued until both sampling sufficiency (in terms of reflecting the diversity of the target population) and theoretical saturation were deemed to have been reached (Seidman 2006); this led to an interview and interviewee survey sample of 35 teachers.

\section{Data analysis, interpretation and reporting}

Both qualitative and quantitative data were used to address each research objective, with the exception of the objective that concerned non-design-related factors affecting the impact of professional development (because this objective was added during data analysis to reflect important findings that had emerged from the qualitative interview data). Thematic analysis (Braun and Clarke 2006) and constructivist grounded theory (Charmaz 2000, Charmaz 2003, Charmaz 2006, Charmaz 2008) were initially used to analyse the qualitative data. This analysis included coding and categorising various forms of professional development, identifying themes in teachers' descriptions of the design and impact of these professional development forms, and identifying the additional, non-design-related factors and how (in teachers' views) these affected the impacts of professional development. Means, standard deviations, confidence intervals, simple correlation, multiple regression and analyses of 
variance were used to analyse the quantitative data in terms of: (a) teachers' perceptions of the design and impact of various forms of professional development; (b) associations between the design and impact of professional development; and (c) differences between Arab and Western teacher's perceptions of the design and impact of professional development.

The qualitative and quantitative analyses were conducted separately in an attempt to allow us to 'listen' to each data set. The indications of these analyses were then brought together to allow holistic conclusions to be drawn in relation to each research objective, as recommended by Bryman (2007). In a number of areas, qualitative findings were used to confirm and (to some extent) explain the quantitative findings, as is common in mixed methods research. However, all analyses and integrative processes were underpinned by the interpretivist recognition that the teachers' accounts (in both quantitative and qualitative forms) and the patterns identified across those accounts (again, using both quantitative and qualitative techniques to identify patterns) reflected teachers' constructions of meaning and not absolute truth about either the nature or the impact of professional development in the Abu Dhabi context.

Analyses were also underpinned by recognition of the complexities of conducting research across cultural boundaries (Kvale 2007, Harkness et al. 2010), leading us to hold the apparent results 'loosely' and consider how culture and context might be influencing teachers' responses. For example, both qualitative and quantitative data indicated that the Arab teachers had more positive perceptions of professional development activities that were more formal in style and that were led by school administrators, whereas the Western teachers had more positive perceptions of informal professional development activities that were led by subject specialists. In this case, the indications of both the quantitative and qualitative data were interpreted in the light of research findings from the field of intercultural communication: Arab cultures tend to involve a higher 'power distance', 
reflected in greater respect for authority, greater distance between people in 'senior' and 'junior' or 'expert' and 'novice' position, and greater compliance with the directives and decisions of those in positions of power (Hofstede 1986, Hofstede et al. 2010, Neuliep 2011). Thus, rather than concluding that either the formal, school administrator-led forms of professional development or the informal, subject specialist-led forms of professional development were 'better' (either in general or for a particular group of teachers), the interpretation of the data-in-context was that the differing cultural norms of the Arab and Western teachers may have led to the difference in the two groups' perceptions of these forms of professional development.

The reporting of results integrated the quantitative and qualitative data in different ways - sometimes presenting these within a single paragraph and sometimes in consecutive paragraphs or sub-sections - but the qualitative and quantitative results were integrated wherever possible. Further, having drawn on both qualitative and quantitative data to draw conclusions about each individual research objective, a broader, cross-study discussion integrated the findings across all objectives and data sources. This discussion considered how the results for the various research objectives related to each other and highlighted themes and findings that (in our interpretation) appeared to be of particular importance across the data collected. In this way, the interpretation and reporting of findings enacted Bryman's $(2007,21)$ characterisation of mixed methods research:

\footnotetext{
In genuinely integrated studies, the quantitative and qualitative findings will be mutually informative. They will talk to each other ... and the idea is then to construct a negotiated account of what they mean together ... Mixed methods research ... is about forging an overall or negotiated account of the findings that brings together both components of the conversation or debate.
}

This section has necessarily provided only a brief overview of the ways in which data analyses were conducted for the study. Readers seeking more detail in these areas are referred 
to the original study by McChesney (2017).

\section{Quality considerations}

Although various quality criteria for mixed methods research have been proposed, these often reflect a post-positivist worldview in which qualitative and quantitative data are used to develop a single, definitive and generalisable understanding of the research topic (Howe 2012, Torrance 2012). For our study, in contrast, we drew on practical recommendations in the form of listings of specific research practices that Creswell and Miller (2000) and by Willis (2007) argue may be used to enhance quality in interpretivist and social constructivist research. These practices involved member checks, extended researcher experience in the research environment, peer review, researcher journaling, audit trails, disconfirming evidence, and the provision of thick, rich qualitative description.

A further quality consideration related to the appropriateness of future users' interpretation and application of our findings. Although interpretivist researchers focus primarily on context-specific understandings, the findings of interpretivist research may be generalised to the extent that new contexts (in which the research may be applied) are similar to the original study context (Willis 2007). To allow future users to assess this contextual similarity, it is critical for interpretivist researchers to provide rich, detailed contextual description. The written account of our study, therefore, included extensive information about the study context: the geographical location, past and present education reform efforts, professional development policy and practice, and the teaching workforce at the time the study was conducted (McChesney 2017).

\section{Summary of selected findings}

For completeness, we now provide a brief overview of selected findings of the study (McChesney, 2017). Teachers reported participating in a wide range of professional 
development activities, which we classified into 11 categories. Overall, the teachers appeared to feel that most of the forms of professional development that they had participated in (a) reflected literature-based principles of effective professional development design (Garet et al. 2001, Desimone 2009) and (b) had resulted in positive impacts. However, it was of concern that the teachers reported the least effective designs as well as the lowest impacts for the forms of professional development that the largest numbers of teachers had participated in (typically forms that were mandatory within the Abu Dhabi public school context).

The design features of the professional development activities appeared to be related to the impacts of professional development, a finding that is in line with the indications of existing literature (Garet et al. 2001, Desimone 2009). Thus, teachers in our study felt (in general) that professional development led to greater impacts when the professional development reflected: a subject-specific content focus, active learning approaches, coherence with other policies and expectations in the local context, extended and substantial duration, and collective participation by groups of teachers (Desimone, 2009; McChesney, 2017). However, the teachers indicated that other, non-design-related factors also affected the extent to which professional development resulted in impacts for teachers, students and schools. Rich insights were gained regarding the importance of: teachers' access to professional development opportunities; their school contexts; the extent to which professional development approaches afforded teacher agency; and the extent to which teachers were able to access and construct meaning related to the content of professional development (McChesney, 2017).

\section{Discussion and conclusions}

Using the example of our recent study, we have demonstrated how the interpretivist paradigm can underpin and inform the whole of a mixed methods research study. This study may serve 
as a useful exemplar for other researchers interested in how a holistic paradigmatic stance (and, specifically, the interpretivist stance) may be used to frame a mixed method study. Bryman (2007) has reported researchers' perception of a lack of mixed method research exemplars, and Alise and Teddlie (2010) have shown that researchers reporting empirical studies (mixed method or otherwise) seldom make explicit their paradigmatic position or how this influenced the research. We suggest, therefore, that there is much value in the field developing a collection of 'annotated exemplars' such as ours — not merely accounts of different mixed method studies (of which there are already vast numbers) but, rather, accounts that provide explicit commentary on the how and why questions behind the design and conduct of the study.

At a more philosophical level, we also hope that the example of our study may contribute to disrupting the automatic associations that some researchers may hold in relation to research paradigms. We have shown, for example, how quantitative methods and concepts such as 'impact' and 'differences' (all of which may be assumed to be associated with postpositivist research) can be incorporated in an interpretivist study. Although there may be limitations to what methods and paradigms can meaningfully be combined, we hope that the practical illustration provided in our study usefully complements the existing theoretical calls for movement away from binary method-paradigm associations and assumptions.

The relationship between research methods and research paradigms may be thought of as a 'which came first - the chicken or the egg?' scenario (Mertens 2012). In some cases, researchers' preferred paradigmatic stance or the paradigms accepted by bodies responsible for research funding or approval may drive the selection of research methods. In other cases, methods may be selected first (again, possibly due to researcher preferences or contextual constraints) and then a suitable paradigm may be sought from which to frame and ensure the coherence of the study. 
Regardless of 'which comes first', however, the selection of either particular research methods or one or more research paradigms does not automatically imply a particular selection for the other (Guba and Lincoln 1994, Crotty 1998, Johnson and Onwuegbuzie 2004, Gray 2013). Rather, both methods and paradigms should be intentionally and thoughtfully selected — and then integrated — for any research study.

Although we have argued here for a flexible approach to selecting a single paradigm to frame a mixed method study, we recognise that the possibilities for combining paradigms with research methods are not limitless. Some research methods may, indeed, be fundamentally linked (or fundamentally incompatible) with particular paradigmatic positions (Hathcoat and Meixner 2017)—so we do not wish to suggest a 'free-for-all' approach to combining paradigms and methods. If methods that are fundamentally linked to a particular paradigm are to be used in a mixed method study, the question for the researcher would be whether the other methods being proposed could be conducted within the same paradigm in order to allow for a holistic paradigmatic stance across the entire study. If methods that are fundamentally incompatible with a particular paradigm are to be used in a mixed method study, the researcher should recognise this and select a paradigmatic stance that will allow the proposed methods to be enacted with integrity.

In our view, what is ultimately most important is:

(1) That the paradigmatic or philosophical underpinnings of any research study be explicitly stated (Alise and Teddlie 2010, Creswell and Plano Clark 2011, ShannonBaker 2016);

(2) That both the paradigm(s) and methods selected be suitable to allow the aims and objectives of the study to be met (Creswell, Plano Clark et al. 2003); and 
(3) That researchers demonstrate how the research methods and the overall conduct of the study reflect or acknowledge the chosen paradigm(s), making explicit and justifying the decisions involved in designing the study.

The above criteria need not only apply to mixed methods research. However, perhaps it is in the more complex context of mixed methods research that there is the greatest risk of (all of) these criteria not being met — and therefore the greatest need for careful attention to such matters. Certainly, past reflections on the state of the mixed methods research field indicate that further progress is needed in these respects (Alise and Teddlie 2010, ShannonBaker 2016). As Greene and Caracelli $(1997,5)$ cautioned, 'using multiple and diverse methods is a good idea, but is not automatically good science ... Lacking justification and planning, mixed method decisions may not be defensible.' In our view, this justification and planning must include consideration of method-paradigm coherence. 


\section{References}

Alise, M. A., and C. Teddlie. 2010. "A Continuation of the Paradigm Wars? Prevalence Rates of Methodological Approaches across the Social/Behavioral Sciences." Journal of Mixed Methods Research 4 (2): 103-126.

Bazeley, P. 2009. "Editorial: Integrating Data Analyses in Mixed Methods Research." Journal of Mixed Methods Research 3 (3): 203-207.

Bergman, M. M. 2010. "On Concepts and Paradigms in Mixed Methods Research." Journal of Mixed Methods Research 4 (3): 171-175.

Biesta, G. J. J. 2010. Pragmatism and the Philosophical Foundations of Mixed Methods Research. In SAGE Handbook of Mixed Methods in Social and Behavioral Research, edited by A. Tashakkori and C. Teddlie, 95-118. Thousand Oaks: Sage.

Braun, V., and V. Clarke. 2006. "Using Thematic Analysis in Psychology." Qualitative Research in Psychology 3 (2): 77-101.

Bryman, A. 2007. "Barriers to Integrating Quantitative and Qualitative Research." Journal of Mixed Methods Research 1 (1): 8-22.

Charmaz, K. 2000. Constructivist and Objectivist Grounded Theory. In Handbook of Qualitative Research. N. K. Denzin and Y. S. Lincoln, 509-535. Thousand Oaks, CA, Sage.

Charmaz, K. 2003. Qualitative Interviewing and Grounded Theory Analysis. In Inside Interviewing: New Lenses, New Concerns, edited by J. A. Holstein and J. F. Gubrium, 311-330. Thousand Oaks: Sage.

Charmaz, K. 2006. Constructing Grounded Theory: A practical guide through qualitative analysis. London: Sage.

Charmaz, K. 2008. Constructionism and the Grounded Theory Method. In Handbook of Constructionist Research, edited by J. A. Holstein and J. F. Gubrium, 397-412. New York, NY, Guilford.

Cohen, L., L. Manion and K. Morrison. 2007. Research Methods in Education. Oxford: Routledge.

Creamer, E. G. 2018. An Introduction to Fully Integrated Mixed Methods Research. Thousand Oaks: Sage.

Creswell, J. W. 2010. Mapping the Developing Landscape of Mixed Methods Research. In SAGE Handbook of Mixed Methods in Social and Behavioral Research, edited by A. Tashakkori and C. Teddlie, 45-68. Thousand Oaks, CA, Sage.

Creswell, J. W. 2014. Research Design: Qualitative, Quantitative, and Mixed Methods Approaches. Thousand Oaks: Sage.

Creswell, J. W., and D. L. Miller. 2000. "Determining Validity in Qualitative Inquiry." Theory into Practice 39 (3): 124-130.

Creswell, J. W., and V. L. Plano Clark. 2011. Designing and Conducting Mixed Methods Research. Thousand Oaks: Sage.

Creswell, J. W., V. L. Plano Clark, M. L. Gutmann, and W. E. Hanson. 2003. Advanced Mixed Methods Research Designs. In Handbook of Mixed Methods in Social and 
Behavioral Research, edited by A. Tashakkori and C. Teddlie, 209-240. Thousand Oaks, CA, Sage.

Crotty, M. 1998. The Foundations of Social Research: Meaning and Perspective in the Research Process. Thousand Oaks: Sage.

Denzin, N. K. 2012. "Triangulation 2.0." Journal of Mixed Methods Research 6 (2): 80-88.

Desimone, L. M. 2009. "Improving Impact Studies of Teachers' Professional Development: Toward Better Conceptualizations and Measures." Educational Researcher 38 (3): 181-199.

Fetters, M. D., and J. F. Molina-Azorin. 2017a. "The Journal of Mixed Methods Research Starts a New Decade: Perspectives of Past Editors on the Current State of the Field and Future Directions." Journal of Mixed Methods Research 11 (4): 423-432.

Fetters, M. D., and J. F. Molina-Azorin. 2017b. "The Journal of Mixed Methods Research Starts a New Decade: The Mixed Methods Research Integration Trilogy and its Dimensions." Journal of Mixed Methods Research 11 (3): 291-307.

Garet, M. S., A. C. Porter, L. M. Desimone, B. F. Birman, and K. S. Yoon. 2001. "What Makes Professional Development Effective? Results from a National Sample of Teachers." American Educational Research Journal 38 (4): 915-945.

Giddings, L. S. 2006. "Mixed-Methods Research: Positivism Dressed in Drag?" Journal of Research in Nursing 11 (3): 195-203.

Gray, D. E. 2013. Doing Research in the Real World. Thousand Oaks: Sage.

Greene, J. C. 2005. "The Generative Potential of Mixed Methods Inquiry." International Journal of Research and Method in Education 28 (2): 207-211.

Greene, J. C. 2007. Mixed Methods in Social Inquiry. San Francisco: Wiley.

Greene, J. C. 2008. "Is Mixed Methods Social Inquiry a Distinctive Methodology?" Journal of Mixed Methods Research 2 (1): 7-22.

Greene, J. C., and V. J. Caracelli. 1997. "Defining and Describing the Paradigm Issue in Mixed-Method Evaluation." New Directions for Evaluation 74 (5-17).

Greene, J. C., and J. N. Hall. 2010. Dialectics and Pragmatism: Being of Consequence. In Sage Handbook of Mixed Methods in Social and Behavioral Research, edited by A. Tashakkori and C. Teddlie, 119-143. Thousand Oaks: Sage.

Guba, E. G., and Y. S. Lincoln. 1989. Fourth Generation Evaluation. Newbury Park: Sage.

Guba, E. G., and Y. S. Lincoln. 1994. Competing Paradigms in Qualitative Research. In Handbook of Qualitative Research, edited by N. K. Denzin and Y. S. Lincoln, 105117. Thousand Oaks: Sage.

Hall, J. N. 2013. "Pragmatism, Evidence, and Mixed Methods Evaluation." New Directions for Evaluation 138: 15-26.

Hall, R. 2013. Mixed Methods: In Search of a Paradigm. In Conducting Research in a Changing and Challenging World, edited by T. Lê and Q. Lê, 71-78. New York: Nova Science.

Harkness, J. A., M. Braun, B. Edwards, T. P. Johnson, L. Lyberg, P. P. Mohler, B. Pennell, and T. W. Smith (Eds.). 2010. Survey Methods in Multinational, Multiregional, and Multicultural Contexts. Hoboken: Wiley. 
Hathcoat, J. D., and C. Meixner. 2017. "Pragmatism, Factor Analysis, and the Conditional Incompatibility Thesis in Mixed Methods Research." Journal of Mixed Methods Research 11 (4): 433-449.

Hesse-Biber, S. 2010. "Qualitative Approaches to Mixed Methods Practice." Qualitative Inquiry 16 (6): 455-468.

Hofstede, G. H. 1986. “Cultural Differences in Teaching and Learning.” International Journal of Intercultural Relations 10: 301-320.

Hofstede, G. H., G. J. Hofstede, and M. Minkov. 2010. Cultures and Organizations: Software of the Mind (3rd ed.). New York: McGraw-Hill.

Howe, K. R. 2012. "Mixed Methods, Triangulation, and Causal Explanation." Journal of Mixed Methods Research 6 (2): 89-96.

Johnson, R. B. 2017. "Dialectical Pluralism: A Metaparadigm whose Time has Come." Journal of Mixed Methods Research 11 (2): 156-173.

Johnson, R. B., and A. J. Onwuegbuzie. 2004. "Mixed Methods Research: A Research Paradigm whose Time has Come." Educational Researcher 33 (7): 14-26.

Johnson, R. B., A. J. Onwuegbuzie, and L. A. Turner. 2007. "Toward a Definition of Mixed Methods Research." Journal of Mixed Methods Research 1 (2): 112-133.

Kuhn, T. S. 1970. The Structure of Scientific Revolutions. Chicago: University of Chicago Press.

Kvale, S. 2007. Doing Interviews. London: Sage.

Lincoln, Y. S. 1990. The Making of a Constructivist: A Remembrance of Transformations ast. In The Paradigm Dialog, edited by E. G. Guba, 67-87. Newbury Park: Sage.

Lincoln, Y. S., and E. G. Guba. 2003. Paradigmatic Controversies, Contradictions, and Emerging Confluences. In The Landscape of Qualitative Research: Theories and Issues, edited by N. K. Denzin and Y. S. Lincoln, 253-291. London: Sage.

Mackenzie, N. M., and S. Knipe. 2006. "Research Dilemmas: Paradigms, Methods and Methodology." Issues in Educational Research 16 (2): 193-205.

McChesney, K. 2017. "Investigating Teachers' Experiences of Professional Development within a Major Education Reform in the Emirate of Abu Dhabi." PhD diss., Curtin University.

McChesney, K., and J. M. Aldridge. 2018. "A New Tool for Practitioner-led Evaluation of Teacher Professional Development." Teacher Development 22 (3): 314-338.

Mertens, D. M. 2012. "What Comes First? The Paradigm or the Approach?" Journal of Mixed Methods Research 6 (4): 255-257.

Morgan, D. L. 2007. "Paradigms Lost and Pragmatism Regained: Methodological Implications of Combining Qualitative and Quantitative Methods." Journal of Mixed Methods Research 11 (1): 48-76.

Neuliep, J. W. 2011. Intercultural Communication: A Contextual Approach (5 $5^{\text {th }}$ ed.). Los Angeles: Sage.

Onwuegbuzie, A. J., R. B. Johnson, and K. M. T. Collins. 2009. "Call for Mixed Analysis: A Philosophical Framework for Combining Qualitative and Quantitative Approaches." International Journal of Multiple Research Approaches 3 (2): 114-139. 
Onwuegbuzie, A. J., and N. L. Leech. 2005. "On Becoming a Pragmatic Researcher: The Importance of Combining Quantitative and Qualitative Research Methodologies." International Journal of Social Research Methodology 8 (5): 375-387.

Schwandt, T. A. 1998. Constructivist, Interpretivist approaches to Human Inquiry. In The landscape of qualitative research: Theories and issues, edited by N. K. Denzin and Y. S. Lincoln, 221-259. Thousand Oaks, CA, Sage.

Seidman, I. 2006. Interviewing as Qualitative Research: A Guide for Researchers in Education and the Social Sciences. New York: Teachers College Press.

Shannon-Baker, P. 2016. "Making Paradigms Meaningful in Mixed Methods Research." Journal of Mixed Methods Research 10 (4): 319-334.

Tashakkori, A., and J. W. Creswell. 2007a. "Exploring the Nature of Research Questions in Mixed Methods Research." Journal of Mixed Methods Research 1(3): 207-211.

Tashakkori, A., and J. W. Creswell. 2007b. "The New Era of Mixed Methods." Journal of Mixed Methods Research 1 (1): 3-7.

Teddlie, C., and A. Tashakkori. 2003. Major Issues and Controversies in the use of Mixed Methods in the Social and Behavioral Sciences. In Handbook of Mixed Methods in Social and Behavioral Research, edited by C. Tashakkori and C. Teddlie, 3-50. Thousand Oaks: Sage.

Teddlie, C., and A. Tashakkori. 2009. Foundations of Mixed Methods Research: Integrating Quantitative and Qualitative Approaches in the Social and Behavioral Sciences. Thousand Oaks: Sage.

Torrance, H. 2012. "Triangulation, Respondent Validation, and Democratic Participation in Mixed Methods Research." Journal of Mixed Methods Research 6 (2): 111-123.

Willis, J. W. 2007. Foundations of Qualitative Research. Thousand Oaks: Sage.

Yin, R. K. 2006. "Mixed Methods Research: Are the Methods Genuinely Integrated or Merely Parallel?" Research in the Schools 13 (1): 41-47. 